\title{
Family Members' Experiences: People with Comorbid Bipolar and Substance Use Disorder
}

\author{
Uwarren September ${ }^{1} \&$ Anna-Marie Beytell ${ }^{2}$ \\ 1. University of the Western Cape, Cape Town, South Africa \\ 2. Social Work Department, University of the Western Cape, Robert Sebokwe Road, Cape Town 7535, \\ South Africa
}

\begin{abstract}
People with comorbid bipolar and substance use disorders are complex, whose families experienced challenges contributing significantly to their burden of care. The aim of the study was to explore these lived experiences of family members caring for relatives, as well as the situations or contexts in which they experience these. A qualitative phenomenological research approach with explorative, descriptive research designs was adopted. Indepth phenomenological interviews were done with six purposive selected participants. Phenomenological data analyses focusing on the textural (lived experience) and structural (the context in which it was experienced) were followed after data collection. The lived experiences of participants included feelings of helplessness and emotional and physical exhaustion, as well as the causes of these feelings. The situations contributing to these feelings included non-compliance with prescribed medicine for bipolar disorder combined with drug abuse as well as a threat to the safety of the patient and others, stigmatisation, embarrassment and shame.
\end{abstract}

Keywords: comorbidity, bipolar disorder, substance abuse, family, caregiver

The prevalence of mental disorders is high and contributed significantly to the burden of disease globally. A systematic review and meta-analysis on the global prevalence of mental disorders from 1980 to 2013 across 63 countries found that one in five respondents has a mental disorder during the 12 months before the assessment and 29.2\% respondents had a mental disorder during their lifetimes (Steel et al. 2014).

Mental and substance disorders have contributed to 183.9 million or $7.4 \%$ of all disability adjusted life years (DALYs) and 8.6 million or $22.9 \%$ of life lost to premature mortality (YLLs) globally. Mental and substance use disorders contributed to 175.3 million of years lived with disability (YLDs), which were the leading cause of YLDs globally. These findings have been subtracted from the Global Burden of Diseases Study in 2010 (Whiteford et al. 2013). Ferrari et al. (2016) deducted data from the findings of the Global Burden of Disease Study in 2013 and found that the prevalence and burden of bipolar disease were 32.7 million in 1990 and 48.8 million in 2013, which are a $49.1 \%$ increase. Bipolar disease contributed to 9.9 million or $0.4 \%$ (DALYs) and $1.3 \%$ of the global YLDs. Females with bipolar disorder accounted for 5.5 million and males for 4.4 million DALYs globally. A significant finding was that DALYs have increased from 10 years and peaked at 20 years and then decreased.

A survey of South African Stress and Health (SASH) indicated that $16.5 \%$ of the South African population suffer annually with a common mental illness such as depression and anxiety (Corrigal et al. 2007).

A diagnosis of mental illness is aggravated by the use and abuse of substances, which is then diagnosed as comorbidity between mental illness and substance abuse. A comorbid diagnosis of a mental illness and substance abuse is prevalent in 60\% of the patients using psychiatric services in Western Cape (Botha et al. 2008). A survey conducted by Weich and Pienaar (2009) at Stikland Hospital in Western Cape found that $51 \%$ of psychiatric inpatients have been diagnosed with substance use disorder. Patients included 8\% substance- 
induced psychiatric disorders, with $1 \%$ substance-induced mood disorder and $7 \%$ substance-induced psychotic disorders.

Mental illness and substance abuse result in high levels of risk behaviour and injuries, which contribute significantly to the burden of disease in Western Cape (Nora and Volkow 2010). A research study conducted by the Medical Research Council (MRC) in 2005 as cited in Corrigal et al. (2007) concluded that substance abuse, as well as mental illness, correlates with less capital and a high incidence of community violence.

Our study has focused on a comorbid diagnosis of bipolar and substance use disorders. Bipolar disorder is a severe and often chronic disorder with lifetime prevalence rates of $6.5 \%$ of the general population. The rates of alcohol and other substance use disorders are significantly higher in persons with bipolar disorder than in the general population and are usually associated with mortality and morbidity (Vornic and Brown 2006). A Brazilian study examined the impact of alcohol abuse and dependence on bipolar patients and found that the clinical severity, functional impairment and quality of life were poor (Cardoso et al. 2008). Research to determine the lifetime prediction of suicide attempts in comorbid substance use and bipolar disorder patients found a $39 \%$ lifetime rate of attempted suicide by people with a comorbid diagnosis of bipolar and substance use disorders, and a $23 \%$ rate in patients without comorbid substance use disorders (Dalton et al. 2003).

Treatment of people with a psychiatric disorder, especially when other factors such as comorbidity with substance abuse exist, is complex but irrespective of these factors, treatment has changed globally and in South Africa. Deinstitutionalisation of patients with integration in communities is proposed and included in the South African Mental Health Care Act (Republic of South Africa 2002). The rationale to change from institutional to community-based care was based on stigmatisation of users and their families, human rights violations and increased disability of clients associated with admissions in psychiatric hospitals (Corrigal et al. 2007).

Public psychiatric hospitals focus on care and rehabilitation of psychiatric patients in need of special care, and when these patients are discharged, they receive community-based care in residential facilities and on a primary health care level (Republic of South Africa 2002; Uys and Middleton 2014). For this transition to be effective, alternative care arrangements should be established before patients are discharged (Corrigal et al. 2007).

Measures to reform mental health services in South Africa include integration into general medical services with units/wards in general hospitals where patients can be assessed for $72 \mathrm{~h}$. Community mental health services which include outpatient services, day centres, hospital diversion programmes, crisis teams, group homes, halfway houses and case management are included after discharge from a psychiatric facility (Corrigal et al. 2007).

Deinstitutionalised programmes have not developed as planned which resulted in patients with mental disorders being neglected, vulnerable and with insufficient services focusing on families' physical, emotional and social needs. The consequences of inadequate legislation and resources allocated to specialist mental health services result in low income and emotionally stressed families, which experience poor quality of life (Swartz et al. 2005).

A lack of funding contributes to a lack of treatment for patients with a psychiatric disorder and remains a developmental area for mental health care users and their families. Policy and legislation are not appropriate or effective due to a lack of reliable data, and are necessary to plan proper services and assess and redress inequalities experienced by the population affected by mental health (Lundt et al. 2010).

\section{Families'/Caregivers' Experiences Caring for People with Mental Disorders}

A family taking care of a relative with a mental illness is usually doing it because of the emotional connection they have and may feel obliged to take care of their relative. Families are often uneducated, uninformed and ignorant about mental illness as well as the specific diagnosis. This results in families feeling stressed, burdened and not wanting to take responsibility for their relative. Families experience problems caring for a mentally ill relative because of behaviour changes of the relative, especially when there is comorbidity between substance abuse and mental illness. Diagnosis, help-seeking behaviour and treatment are difficult, and the family must deal with the behaviour of such a patient. The family experiences a crisis, in many instances without assistance on how to deal with it which results in stress and worry. The needs of the mentally ill member become paramount, but the needs of family members are also important (Flisher et al. 2008; Uys and Middleton 2014). 
Families and carers experience a sense of burden when caring for a person with a mental illness (Uys and Middleton 2014; Fujino and Okamura 2009). The magnitude of the burden on families who care for patients with psychiatric illness is emphasised by the Mental Health Foundation indicating that about 450 million people globally have a mental illness, and about one in four families has a relative with a mental disorder or behaviour problems (Mental Health Foundation cited in Halliwell et al. 2007).

The burden on families caring for patients with a bipolar mood disorder is evident in findings of studies. A longitudinal study conducted on family burden amongst relatives of patients with bipolar affective disorder during the manic phase at admission and 4 weeks after discharge found that more than $90 \%$ of family members reported severe subjective (rated by the relative or carer) and objective burden (rated by interviewer) on admission; none of the families was free of strain. The severe burden was rated in a quarter (23\%) of family members, whilst subjectively, none of the family members reported severe burden. It is evident from the study that most of the family members initially experienced severe strain and that the burden decreases with time when caring for patients (Maji et al. 2012). However, a longitudinal study conducted by Herua and Ryan (2004) found that the overall family functioning, except for behaviour control, was unchanged after a year, and was in the unhealthy range of all dimensions of life.

Socio-economic factors, which are evident in the South African context, complicate the situation. The Burden Disease Reduction project in the Western Cape emphasised the correlation between mental health and other socio-economic obstacles including poverty, unemployment, alienation, teenage pregnancies, domestic violence and poor family functioning. An integration of mental health interventions with other poverty and development strategies is, therefore, a necessity in mental health treatment (Flisher et al. 2008). Families stay in a poor resourced neighbourhood with insufficient housing, schools and services, which contribute to poor health, low education levels and no occupational attainment (Thompson et al. 2003; Saegert and Evans 2003). These factors result in experiencing excessive burdens of care. Unemployment or having a low income, low level of education and/or having no skills might contribute to having a high risk of experience a mental illness (Meltzer et al. 2002). Financial problems can be both a cause and a consequence of mental illness (Mental Health Foundation cited in Halliwell et al. 2007).

\section{Aim of the Study}

The aim of the study was to explore and describe the lived experiences of family members caring for relatives admitted in a psychiatric hospital, and the contexts in which these occurred.

\section{Method}

A qualitative research approach was used. This approach provided an in-depth understanding of the participants' perspective and subjective personal data about their experiences whilst caring for a family member with a comorbid diagnosis of bipolar and substance abuse. Qualitative research is used to explore and understand meaning that people give to their experiences, social contexts, values, opinions and behaviours (Creswell 2013; Green and Thorogood 2009).

We employed an explorative, descriptive research design. An explorative research design focuses on learning about the unknown (De Vos et al. 2011). We explored a phenomenon to obtain new knowledge to understand the participants who are taking care of a family member with comorbid bipolar and substance use disorders admitted to a psychiatric hospital. We employed a descriptive research design, which is a more intensive examination of specific detail of a situation, social setting or relationship. A detailed description of the lived experiences and contexts/situations in which the family member experienced these discussed in the results of the research.

We have used a phenomenological strategy of enquiry during the research. Phenomenological studies search for the meaning, structure and essence of lived experiences of individuals or a group around a specific phenomenon (Christensen et al. 2010).We obtained a textural description of what participants experienced when taking care of their relative being diagnosed with a comorbid diagnosis of bipolar and substance use disorders and a structural description on the context or situation of the experience, which provides an overall picture of the experience of participants caring for their relative with a comorbid diagnosis of bipolar and substance use (De Vos et al. 2011; Creswell 2013). 


\section{Sample}

Non-probability purposive sampling was used during the study because we searched for participants which can provide rich information resulting from first-hand experiences and knowledge in caring for a family member with a diagnosis of bipolar and substance use (Donalek and Soldwisch 2004). Relatives of female patients, who had been diagnosed with comorbid bipolar and substance use disorders, were purposively selected. These patients were admitted to a female admission ward, in a psychiatric hospital in Western Cape, South Africa. The patients, as well as families, were unknown to us. Relatives were from both genders and age group. We interviewed identified individuals until saturation was reached and no new information was obtained during the interviews (De Vos et al. 2011). Details on the number of years caring for the patient were included to ensure that we get rich information. We include the number of re-admissions of the patients in the demographic data because the number of re-admissions could be as a result or contribute to the burden which family members experienced whilst caring for the patient (Table 1).

\section{Data Collection}

We used in-depth, unstructured phenomenological interviews to understand people's views on their lived experiences whilst caring for a family member with a comorbid diagnosis of bipolar and substance use disorders. The mental health facility admits patients from various language and cultural groups in Western Cape. Interviews were, however, conducted in English. The duration of interviews was $45 \mathrm{~min}$ to $1 \mathrm{~h}$. Two questions as suggested by Creswell (2013) for phenomenological interviews, which include "Tell me about your experiences when you take care of your relative." The participant has given information and we then ask questions on the situations in which that happen. We used attentive listening, probing, reflecting and silences as interview skills during the interview and clarification and summary to ensure that we are clear about the responses of the participants.

\section{Data Analysis}

We used inductive data analysis to ensure that we get the lived experiences of participants. The personal experiences of the participants were described. A list of statements was developed and grouped into themes and sub-themes. We used an independent coder, which used the same method of analysis. When both groups finished their analysis, we met to discuss the data to get rich information and enhance trustworthiness in qualitative research. A description of "what" the participant experienced was made with verbatim examples (textural description) and followed by $\mathrm{Bhow}^{\wedge}$ the experiences happened (structural description) where the

Table 1 Demographic details of participants and patients

\begin{tabular}{lllllll}
\hline Participant & $\begin{array}{l}\text { Caregiver } \\
\text { gender }\end{array}$ & $\begin{array}{l}\text { Age of family } \\
\text { member (caregiver) }\end{array}$ & $\begin{array}{l}\text { Age of } \\
\text { patients }\end{array}$ & $\begin{array}{l}\text { Years of experience } \\
\text { caring for patient }\end{array}$ & $\begin{array}{l}\text { Re-admissions } \\
\text { of patient }\end{array}$ & $\begin{array}{l}\text { Relationship } \\
\text { with patient }\end{array}$ \\
\hline A & Female & 59 & 33 & 18 & 5 & Mother \\
B1 & Female & 70 & 19 & 17 & 2 & Grandmother \\
B2 & Male & 77 & 19 & 17 & 2 & Grandfather \\
C & Female & 35 & 57 & 27 & 3 & Daughter \\
D & Male & 61 & 37 & 13 & 8 & Father \\
E & Male & 47 & 37 & 5 & 1 & Husband \\
F & Female & 46 & 29 & 15 & Mother \\
\hline
\end{tabular}

focus was on the context or setting in which it was experienced was done as proposed by Creswell (2013). A composite description of the experiences incorporating both the textural and structural description was written in the findings of the research. 


\section{Results}

The results of the research focus on the descriptive design of the research. The lived experiences of the participants and the situations/contexts in which these were experienced are described according to the themes and sub-themes identified during the data analysis. Four major themes were identified. Themes 1 and 2 are textural descriptions, and themes 3 and 4 are structural descriptions (Table 2). Inductive reasoning, relevant for phenomenological research (Creswell 2013), has been implemented with a focus on the voices of the people through quotations resulting in themes and sub-themes. Therefore, literature review followed the data analysis. Literature is used in the discussion of the results to accentuate the experiences.

\section{Theme 1: Feelings of Helplessness and Emotional and Physical Exhaustion}

It was significant that all participants initially and very strongly verbalised their feelings of helplessness, with emotional and physical exhaustion. Taking care of a family member with bipolar disorder causes emotional burdens. Caregivers have endured various kinds of stress relating to their relative's disorder, symptoms and disruptive behaviours, as well as the stigmatisation by the society of persons with mental disorder and their relatives. Daily living with a person bipolar disorder results in frustration, which can be exhausting. The unpredictable behaviour and mood changes intrude into households and can be a great stress in relationships, which may lead to outbursts (Perlick et al. 2008; Mondimore 2006).

Participants experienced feelings of hopelessness; depression, anxiety and frustration are intrinsically related to exhaustion and helplessness and the life stage and kinship of the participants to the patient as quoted:

Table 2 Themes and sub-themes

Themes Sub-themes

Theme 1: Feelings of helplessness and emotional and physical exhaustion

Theme 2: Causes of the exhaustion and feelings of helplessness

Theme 3: Participants' experiences of the context of patients' impulsive irrational behaviour of non-compliance to prescribed medicine for bipolar disease combining with drug abuse

Theme 4: Experiences of personal and social consequences of the behaviours

Sub-theme 1: Unpredictable, impulsive, "abnormal" and irrational behaviour of patients

Sub-theme 2: Lack of support systems

Sub-theme 3: Ignorance about the illness aggravated the exhaustion and ability to handle the situation

Sub-theme 1: Safety of self and others

Sub-theme 2: Social stigmatisation, embarrassment and shame

Participant A (Mother): "A child with bipolar and to the substance that she's using and the drugs, and having a drinking, is a very, very bad situation. Due to that, always, I just don't know which way to turn... don't know anymore what to do. I, I really just break down and cry, because it's my child".

Participant B (Grandparents): “This is so exhausting; won't the Lord rather take you away. Because you can't deal with this, at this age. We don't know what anymore with this child".

It is evident that the intensity of the emotions expressed in the statements above, reflecting on the experiences over the years, feelings of hopelessness, depression, anxiety and frustration were intrinsically related to exhaustion and helplessness and the life stage and kinship of the participants. Being hospitalised can be 
distressing and terrifying for both the patient and his or her family. Stressful and sad emotions can be experienced simultaneously if a loved one's ability to function decreases as result of a chronic illness (Last 2009; Haycock 2010).

Children cope with caring for a relative by spending some time alone, just enjoying them not to be burdened with the experience he or she had when taking care of the ill parent. In a case study, a daughter reported that the unpredictability of looking after her mother was the worst part because she never knew what to expect when getting home after school or coming from elsewhere, which led to her experiencing hatred towards her mother for letting her down. Child-headed households might be a result of a child caring for a parent. Circumstances outside the child's control may lead to feeling responsible when incidents occur. People can experience burnout and/or outbursts when taking care of their relative for a long time, which results from being physically tired, emotional and/ or just having had enough. The carer may just leave his or her relative and does not care anymore (Aiken 2010; Haycock 2010; Fast and Preston 2004).

A daughter reflecting on performing tasks relevant to the role of a mother at the age of 12 expressed unresolved feelings of emotional hardship in the following quote:

Participant C (Daughter): "It became a big responsibility for me as well in the house. to look after my brothers and to see that you know that there's food on the table. I mean to make the food and to see that the house was clean, yes that is part of our daily tasks and things but being a 12-year-old and looking after two siblings and whilst you are...the one parent is at work and the one parent is ill. Just wanted to be a child and, I just wanted to be a child and do my thing, you know, and be with my friends. I was always scared, I did not, and I did not know how to deal with it. I just wanted my mommy being normal like a normal mother... I at some stage I got agitated you know. I do not know how to cope with it, I do not know what to do, I just got fed-up also about this illness because it's making her feels all sorts of things and I do not know how to deal with it".

This statement focuses on the devastating sense of responsibility that can be experienced by children when looking after their parent, which can lead to feeling guilty about their parent's illness. Feelings of irritation, unhappiness, fright, uncertainty, concern, misunderstanding and frustration may be experienced by children.

When caregivers cannot cope with the behaviour of their relative, hospitalisation seems to be the best option for the family to manage the situation as expressed by this participant:

Participant D (Father): "Eventually I said, I say I just can't do this anymore and that was about a year ago where I then did only what I had to (referring to hospitalization)".

When a relative gets admitted into a hospital, this can be a relief for the family, especially when mood changes are difficult to handle at home and the patient becomes a danger to him or herself and/or to the family (Fast and Preston 2006).

The carer must eventually perform the roles of the ill relative and sacrifice things they used to do together, as well as alter his/her expectations. Couples and/or relationships that compete with mental illnesses experience complications. To have a loved one with bipolar disorder can increase that complexity, especially when the disorder is not treated and/or not treated adequately. The amount of time and energy being spent in taking care of a relative with bipolar disorder can sometimes influence family members' own well-being and the relationship.

A husband and mother reflect in the statements below on the effects that caring for a relative have on their emotional well-being:

Participant E (Husband): "It was very difficult for me to handle, that I ended up in the hospital myself for three weeks at Crescent Clinic because I didn't know how to handle it”.

Participant F (Mother): "She doesn't want to hear, she doesn't want to hear, she is making her mother sick".

These statements expressed the difficulties associated with bipolar disorder. The disease has major effects on socio-economic functioning and interpersonal relationships across the lifespan. People who do not have bipolar 
disease do not know how awful it is to suffer from the disorder, whilst the people having the disorder know the challenges in caring for someone with the disease (Anti-Ontong 2003; Fast and Preston 2004).

\section{Theme 2: Causes of the Exhaustion and Feelings of Helplessness}

Several conflicting emotions may appear in family and friends when a relative is diagnosed with bipolar disorder. Feelings of helplessness, fear and worry are experienced by spouses, partners and families of people with bipolar disorder (Last 2009; Miklowitz 2010). Recognising a partner's illness, which has resulted in the loss of important aspects of life, may lead to grief. A partner of a bipolar disorder patient may experience overwhelming emotions, hopeless, confusion and bitterness towards the patient, as well as feelings of embarrassment and concealment. Without support, it is possible the caregiver may feel trapped and pressured when caring for their relative with bipolar (Fast and Preston 2006; Tranvag and Kristoffersen 2008; Last 2009).

Three sub-themes emerged from the data collected concerning the causes of exhaustion and feelings of helplessness by the participants who cared for a relative with bipolar disorder. The statements of the participants highlight these sub-themes in the following text:

\section{Sub-Theme 1: Unpredictable/Impulsive, BAbnormal^^/Irrational Behaviour of Patients}

Bipolar disorder may risk family and interpersonal relationships. When describing the emotional instability of bipolar disorder by a partner, sibling, child or parent, the family has the tendency to highlight the threats they face during outbursts, which they felt were not their fault. Families become worried that their relative could become suicidal and/or homicidal during extreme manic episodes and become very emotional and scared if such thoughts are expressed. Patients experiencing such behaviour in an extreme manic state may say insulting, rude and insensitive things, and often caregivers find it very challenging to stay calm, be forgiving and have patience (Miklowitz 2011; Haycock 2010).

The following statements signify abusive, irrational and uncontrollable behaviour experienced by the participants:

Participant A (Mother): "We must watch her continuously; she will come and bath up to five times a day, will let the water run the whole day. She will walk the whole day up and down to the school to her children. Then the school phones and tell me that she again at school...we are even scared when it comes to the electrical equipment and that because she puts it on and she forgets it... takes handy Andy and Jik and things and then she puts her children in the water...she sometimes gets abusive...she will shout at me".

Participant B (Grandparents): "Then I said to F, then get the police, then she gets back to home, then when we talk with her, she tells us, she is older than 18-years old, she can do what she wants to do. I would tell C, you know you should drink your medication. Then she gets angry at us. He said to her, well if you don't want to listen to us, we going to take you back to the hospital then. She then threw the chairs out of the house and screams at us".

Participants B (Grandparents): "She is a compulsive liar and a manipulator. You cannot control her, it's difficult, but it turns into grief for the parents and for the family. And a question of verbal abuse, swears at you, sometimes assault attempted assault".

Participant C (Daughter): "She did weird things put the light on ... wake up in the middle of the night you know. Scream she got panic attacks, constantly or she said it was like a panic attack and she couldn't handle crowds and things and or when the two of us went shopping in the taxi and then she would tell me she just wants to get home".

Participant D (Father): "Irrationality of her behaviour which was we ... at times we thought it was ...linked to drug abuse and at other times we were convinced it was purely mental illness... When she's having an incident she behaves completely differently to what she would normally behave ... she has absconded from every single hospital or institution...located her hiding next to the freeway in the bush which is one of her old tricks and then she would pop out and wave at a car and on the side of the 
road...gets lifts easily with anybody and that's the type of fear her parents live with and which is why we are obsessed with finding her for her safety and then she is in the back of the van".

Participant F (Mother): "Then she maybe was on the road, I mean, when you ask her a piece of bread, then she wants to stab me with a knife and start to make the children nervous, and the little one is already scared at her".

These statements by participants signify that their ill relatives' behaviour causes fear and anxiety, especially when being left alone at home. The behaviour of their relative becomes abusive, verbally and emotionally, but the carer does not want to do or say anything because they are concerned about the safety and unpredictability of the patient. During extreme manic episodes, patients often threaten caregivers of committing suicide or homicide.

Relatives and/or families taking care of a patient with bipolar disorder do not understand that patients have sporadic symptoms and they are more likely to focus on the behaviour of the patient and the effects which result in harsh decisions which can have a negative impact on relationships. Support systems are important during these times. Men who care for their spouse diagnosed bipolar might make more effort to create a support structure. Women, in general, have existing support structures outside the core family (Fast and Preston 2004; Haycock 2010; Miklowitz 2011).

A husband of a patient expressed the difficulty he experienced caring for his wife with bipolar disorder:

Participant E (Husband): "There is a whole turn around in her behaviour from being the calmest person to being violent and aggressive. Then I am the wrong one around this and around that and I don't know if this is caused by the bipolar or what else... that's where things started to get messed-up between us because of her accusations. At times, I am the best husband you can get, and then suddenly I am the one cheating around. After the medication, and she has eaten... then I would give her something to eat she gets calm, then I let her sleep a bit, then I started to wonder, what's going to happen next when she wakes up”.

This behaviour of patients can result in that a partner might stop being involved with his or her ill partner, who does not take care of him or herself, and harsh decisions must be made about their relationship status. Those decisions made may be in the best interest of the partner's emotional well-being because of insecurity. Partners or spouses are constantly aware of the stress factors around them as well as the changes in their partner's mental state, and often, self-doubt is present.

\section{Sub-Theme 2: Lack of Support Systems}

The family is the most important structure for most patients and families, but the caregiving role is a huge burden. If a relative causes persistent embarrassment, the burden is much greater (Mondimore 2006; Tranvag and Kristoffersen 2008). Chadda et al. (2007) maintain that the seriousness of the illness and the disruptive behaviour of patients are vital predictors, associated with high levels of burden. Families find various ways of dealing with the illness, which include finding solutions, support from friends or loved ones or avoiding the problem by finding a 'solution'-such as substance abuse. When not getting the relevant resources, caregivers experience high levels of burden. Caregivers who have emotional coping strategies experience a reduction of being burdened.

The following participants' report on their experiences of a lack of support systems, which aggravates their experience of exhaustion and helplessness:

Participant A (mother): "You got no family that can help you, not as if they don't want to help you, but my family is scared".

Participant B (Grandparents): “We went to an external social worker, but she couldn't help us much". Participant C (Daughter): "It became a big responsibility for me (to look after her) and to look after my brothers and to see that you know that there's food on the table. I mean to make the food and to see that the house was clean, being a 12-year old, I have to be an adult then: do the shopping...” 
Participant D (Father): "She (mother) is unable to cope with any stress or any confrontation at all, so the entire onus or responsibility for D security and safety rested on me. I know on the patient's side as ... side she must feel I am the only person...that actually maintains communication with her from the beginning throughout until I abandoned her".

These responses suggest that resources are seriously lacking in communities, which often leads to caregivers giving up and becoming silent. A comorbid diagnosis of bipolar and substance use disorders affects many; therefore, it is important that the ones affected receive appropriate assistance and support.

\section{Sub-Theme 3: Ignorance About the Illness Aggravates the Exhaustion and Ability to Handle the Situation}

Caregivers have needs whilst caring for their relative with a diagnosis of bipolar and substance use disorders, such as being able to deal with their emotions about their relative's disorder. A need which was expressed is awareness raising and education on the specific illness. Relatives are confused because the diagnosis is difficult to understand. Families need to be informed about their relative's illness because it is expected from them to assist with the person's recovery. Families especially need information after experiencing a manic episode of their significant other, where hospitalisation is needed. There are many misconceptions by family members about drug treatment and psychotherapy. Caregivers need to understand that their relative's behaviour is to some extent determined by genetic and chemical factors (Miklowitz 2011; Aiken 2010).

Participants emphasised the need for awareness raising and education about their relatives' illness in the following statements:

Participant D (Father): “There's so much ignorance amongst the police that just I don't even think half of them have copies of the latest public health".

Participant E (Husband): "I don't know how to deal with bipolar, it is a lot for me, and I don't understand the change in behaviour and how to handle it. It makes me frustrated because it's honestly something I struggle with to adapt to and how to handle. I recently started to read and learn about bipolar on brochures, and newspapers, then I've read, oh this is bipolar, and this is a way to handle it. At that stage, I really didn't know, and it was very difficult for me".

Participant C (Daughter): “So it's not mad it's just an illness. That eventually I came to understand...By reading up on it".

Participant A (Mother): "This is not something I know how to work with, but I'm trying my best, because of the situation she's in. When Doctor called me in and when he spoke to me, then I only broke down, because I didn't know it was like mentally something wrong with her".

Participant B (Grandparent): “I started to hear about drugs, and I didn't know what it is, because I am already old. We didn't know that there are forms that one can complete if they are going on like that and make you mad and threatens you with all suicidal and homicidal stories, and of their little friends and stuff... that we can fill out a form, and let he admit in a place for example, we didn't know about such things".

Participant E (Husband): “This mental disability bipolar, no-one, no-one, a lot of people doesn't even know about bipolar, they don't know what bipolar is, they don't know about the change in behaviour, because you got immediately a label that you are mad".

Caregivers of relatives admitted to hospital often build relationships with the multidisciplinary team with the hope of receiving information, guidance and support. This does not always happen. Families of patients, which do not adhere to treatment and show disruptive behaviour, experience more stress than others. These families develop disappointment and frustration with professionals not helping. It is evident in this sub-theme that the lack of information about the illness from carers and communities and about treatment options aggravates the situation. 
Theme 3: Participants' Experiences of the Context of Patients' Impulsive Irrational Behaviour as Non-Compliance with Prescribed Medicine for Bipolar Disease, Combining with Drug Abuse

Problematic family, peer and work relationships may be triggers of unpredictable behaviour of a patient with bipolar and substance use disorders. No symptom or factor should be seen in isolation. It is important to take the context into consideration when diagnosing a patient with comorbid bipolar and substance use disorders. Factors to consider include financial problems, difficulties related to resuming work or family roles, problems linked to the treatment or medications or relationship and living situational conflicts. People with bipolar disorder tend to stop their treatment, which results in major challenges for caregivers. More than half of the persons diagnosed with bipolar stop using their medication, mostly because of side effects and cultural beliefs. Unless the patient makes a commitment, no one can force him or her to take responsibility for his or her medication (Taylor 2006; Miklowitz 2011; Mondimore 2006; Perlick et al. 2004).

Almost $50 \%$ of patients with bipolar disorder stop their treatment, although the reasons for this behaviour are unspecific. Substances and other comorbidities play a role, which is the most common cause of relapse amongst bipolar patients. A patient who does not fully comply with treatment has a higher risk of hospitalisation. It is also reported that between 40 and $60 \%$ of patients with bipolar disorder have a long-term substance use disorder. Substance abuse can cause similar symptoms to those of bipolar disorder. It is very difficult to determine whether a person has been substance induced, has a major depressive episode or is being bipolar, or a combination of these. The use of illicit drugs may imitate episodes of bipolar, but the mood disorders, which result from substances, are temporary (Colom and Berk 2010; Haycock 2010; Berk et al. 2008; Miklowitz 2011).

Last (2009); Haycock (2010); Fast and Preston (2006) support this by confirming that substance abuse is common amongst patients with bipolar disorder and appears in at least $60 \%$ of patients during the disorder. These authors agree by stating that these substances can prevent the medication from being effective and can endorse bipolar disorder and impulsive irrational behaviour.

The experiences of carers about the context and causes of non-compliance to medication combining with drug abuse refer mostly to patients not taking medicine for depression and, especially in the case of younger patients, dependence on substances as the result of peer relationships as expressed in the following statements:

Participant A (Mother): "Doctor told me she has to stay on her tablets and things and that will calm her down and things like that. But which she is not taking it..."

Participants B (Grandparent): "I was hysterical; I told her you can't go. She didn't want to listen, and she didn't take her medication. She is a compulsive liar and manipulator. They have the ability, to put emphasis on the 'I'. To guide you away from the fact that they are using drugs. They will deny it, deny it all the way".

Participant C (Daughter): “... she wouldn't forget to take it. I don't know now when if she's going to if she comes home how she's going to cope with taking her own medication but I'm sure I'll be able to sort out something ... I'll be able to get somebody to assist her".

Participant D (Father): "I think catalysed by the fact that or not catalysed precipitated by the fact that she had been non-compliant with her medication for two days...but it was almost every single time linked to her non-compliance with her medication".

Participant E (Husband): "When I come home, I wonder what kind of change in behaviour will be there. Then I first run to her medication, and then I see, no, these tablets are too much. That's why I say, she most probably didn't take her medication regularly which could've had an impact on her current admission. As soon as she drinks one or two glasses of beer because that's any way all that she drinks, then it looks to me there is a whole change in her behaviour, of being the calmest person, then I am the wrong one, of being calm to violent and aggressive)".

Participant A (Mother): "She's not taking her medicines, that is what I'm seeing that she's not taking her medicines and due to the drugs and that and at the end of the day, we will just find her, and she might sleep, and she will sleep a whole a few days. The doctor told me she must stay on her tablets and things and that will calm her down and things like that. But which she is not taking it...” 
The participants exemplified that patients do not accept responsibility for taking their medication, and the responsibility often lies with the caregiver to remind the patient to adhere to medication. They also emphasised that the inconsistency of taking medication results from the use of alcohol and/or drugs, which lead to difficulty in becoming stable and can cause a greater risk of unpredictable behaviour such as suicide and or homicide.

\section{Theme 4: Experiences of Personal and Social Consequences of the Behaviours}

Participant's reflections explicitly and implicitly indicate that patient behaviour threatens their own safety, as well as the safety of others, influence family relationships negatively and cause social embarrassment. Two subthemes emerged from the findings of the participants which emphasised the consequences of patients' behaviour experienced by the participants.

\section{Sub-Theme 1: Safety of Self and Others}

Disloyalty, reckless spending, violence, carelessness, irresponsibility and breaking the law are experiences that caregivers must deal with daily when caring for a person with bipolar disorder. Suicide attempts and assaulting another person are amongst the more common behaviours in which a person might break the law during a bipolar episode. A follow-up study for over 30 years found that the death rate was very high amongst bipolar patients, with suicide being the most common cause of death. Suicidal behaviour is displayed by $59 \%$ of patients with bipolar disorder and 56\% attempt commit suicide (Haycock 2010; Vieta 2009; Chessick et al. 2007).

Safety and security are of great concern for the family member and their relative as described as follows:

Participant A (Mother): “I can’t just leave her alone in the house, cause even when I go to church, then sometimes I get a message on the phone or somebody is standing in front of the door and they say, your door is standing wide open. You can't just really, keep on with somebody and that person is going to hit you or whatever... she's very strong.... She pulled out my driving gates, my sliding gates at home, the way some came one day to take her to the hospital".

Participant D (Father): "Patient needs security and safety ... inability to look after themselves and her endangering her own life by spending weeks and weeks in locations amongst them. I'm certainly not racist but Nigerians they prepared to hide her away and you wouldn't know she's in there somewhere".

In practice, it is observed that people with bipolar disorder medicate themselves with street drugs and/ or alcohol and this can make their symptoms worse in the long term. As stated before, the abuse of drugs may alter an episode of an illness, which may get patients to medicate their own illnesses and will worsen the bipolar disorder (Haycock 2010; Sadock and Sadock 2003; Miklowitz 2011). In addition to alcohol, people with bipolar disorder may use street drugs or abuse prescription drugs to self-medicate to manage their moods (Last 2009).

Grandparents referring to 18-year-old patients' behaviour on the streets mentioned the following:

Participants B (Grandparents): "We concluded, that those people are worse, worse drug abusers. They have taught her. I was also threatened by the 28 gangsters or whatever the case may be”.

These statements suggest that patients do not adhere to medication and that illegal substances are a substitute to manage their moods, which makes their conditions worse and causes readmission to the hospital in the long term.

The risk of suicide of bipolar disorder patients ranges between 15 and $25 \%$. A suicide attempt of a family member can have lasting effects on the caregiver. Caregivers experience suicidal ideation and reported health difficulties (Colom and Berk 2010; Chessick et al. 2007).

A daughter mentioned the following about mother trying to commit suicide: Participant C (Daughter): "She sat with a handful of pills and luckily I caught her, and I sat down with her and I said, "mommy, this isn't the way out..."” 
Families experience difficulties adapting to changes in mood, disruptive and/or impulsive behaviour of their ill relative and become aggressive and irritated themselves, without knowing that aggressiveness is not restricted to people living with bipolar disorder.

Bipolar disorder can occasionally display sudden behavioural changes. Aggression and psychosis are two factors which are complicated to deal with. Knowledge about the illness enables caregivers to identify the symptoms of new episodes which lead them to intervene rapidly (Mondimore 2006; Miklowitz 2010; Haycock 2010).

The following statement indicates that the husband reacted with aggression to a patient's aggression towards him.

Participant E (Husband): “This is now my aggression towards her aggression”.

Evidence reveals that stressful circumstances and strongly expressed emotions within a family are often the cause of bipolar disorder and have been described as an important predictor of a setback during the disease. Bipolar disorder affects family relationships, and family relationships affect bipolar disorders. Families are unable to control the occurrence of a manic episode of a relative. The disruptive behaviour can become intolerable to live with. The fear of new relapses is present, even though the illness is stabilised, and every episode is a stressful event for all family members (Colom and Berk 2010; Reinares et al. 2006).

A mother reflected on the effect of her daughter's behaviour on the family:

Participant F (Mother): “Tears families apart, this is what they say TIK does, the drugs...”

\section{Sub-Theme 2: Social Stigmatisation and Embarrassment/Shame}

Individuals being labelled as different and/or believed to have negative characteristics which result in negative emotional reactions and discrimination as well as loss of identity has been defined as stigmatisation. The stigmatisation of patients suffering from a severe mental disease, as well as their families caring for them who reported feeling stigmatised, has been observed globally and contributes to the burden of family caregivers. Families affected by stigmatisation isolate themselves from society and experience depressive moods which can cause them to lose out on opportunities to have valuable resources and enjoyment. Conflicting emotions such as fear, worry, denial, anxiety, hopelessness, anger and even irritability are likely to be experienced by family and friends. One can also be shocked or ashamed of one's relatives' behaviour, especially in public (Gonzalez et al. 2007; Berk et al. 2008; Fast and Preston 2006).

The following participants explicitly mentioned exposure to social embarrassment due to the patient's behaviour. The two men (father and husband respectively) and the daughter of a patient, who from the age of 12 was exposed to the bipolar behaviour of her mother.

Participant E (Husband): “This mental disability bipolar, no-one, no-one, a lot of people doesn't even know about bipolar, they don't know what bipolar is, they don't know about the change in behaviour, because you got immediately a label that you are mad".

Participant C (Daughter): "It seemed embarrassing because there's constantly there are neighbours, friends in and out and you don't want people to know, what, what is.... You don't want people to know what is happening. I felt embarrassed I wouldn't want them to see my mom speaking out of turn to them you know it's speaking maybe in a bad way when she's not supposed to".

Participant D (Father): "She would assault people and pull plates and cups off restaurant tables and an entire restaurant with a hundred and twenty people will be empty".

It is therefore evident that ignorance about the illness and incidents caused by the impulsive behaviours label the patient and cause social embarrassment for the family. The above themes and sub-themes imply that participants acknowledge that they cannot cope with the behaviour of the patients. The only option for them is to try to control it, with the help of medication, police and hospitalisation. 


\section{Conclusion}

Families caring for a person with a comorbid diagnosis of bipolar and substance use disorders experienced feelings of helplessness and emotional and physical exhaustion. Contributing factors to these feelings are unpredictable, impulsive, 'abnormal' irrational behaviour of the patients, as well as lack of support systems. The family caregivers experienced that ignorance of the illness aggravated the exhaustion and ability to handle the situation.

Patients demonstrated irrational behaviour of non-compliance to prescribed medicine for bipolar disease combined with substance abuse. The participants experienced that the behaviour has personal and social consequences because it has an influence on the safety of the patient and others. The behaviour contributes to social stigmatisation and embarrassment or shame of the family.

It is important for multi-professional health care workers to include these experiences and the contexts in which the family members/caregivers experienced these in the treatment of the patients. Treatment should include the family members/carers and their contexts especially if patients are discharged and cared for in communities as proposed. If these factors are excluded, patients with a diagnosis of bipolar and substance use disorders will be re-admitted and treatment will be ineffective.

Compliance with Ethical Standards All procedures followed were in accordance with the ethical standards of the responsible committees on human experimentation (institutional and provincial) and with the Helsinki Declaration of 1975, as revised in 2000 (5). Informed consent was obtained from all participants included in the study.

Ethics were studiously implemented considering the vulnerability of people with mental illness and their families. The study was approved by the Research Committee of the University of the Western Cape, Department of Health: Western Cape and the Psychiatric Hospital.

The purpose of the study was explained to participants using an information sheet before they give informed consent to participate in the study. Participants were informed that they could withdraw at any stage from the study. Confidentiality was maintained by using pseudo names to protect the identity of the patient and family.

Conflict of Interest The authors declare that they have no conflict of interest.

Publisher's Note Springer Nature remains neutral with regard to jurisdictional claims in published maps and institutional affiliations. 


\section{References}

Aiken, C. (2010). Family experiences of bipolar disorder: the ups, the downs and the bits in between. London: Jesica Kingsley Publishers.

Anti-Ontong, D. (2003). Psychiatric nursing: biological and behavioural concepts. Texas: Thomson/Delmar Learning.

Berk, L., Berk, M., Castle, D., \& Lauder, S. (2008). Living with bipolar: a guide to understanding and managing the disorder. Allen and Unwin: Crow's Nest.

Botha, U., Koen, L., Oosthuizen, J., Joska, P., \& Hering, L. (2008). Assertive community treatment in the South African context. African Journal of Psychiatry, 11, 272-275.

Cardoso, B. M., Sant'Anna, M. K., Dias, V. V., Andreazza, A. C., Cerese'r, K. M., \& Fla'vioKapezinski, F. (2008). The impact of co-morbid alcohol use disorder in bipolar patients: a bipolar disorder program Hospital de Clinicas De Porto Algegre. Alcohol, 42, 451-457.

Chadda, R. K., Singh, T. B., \& Ganguly, K. K. (2007). Caregiver burden and coping. Social Psychiatry Psychiatric Epidemology, 42, 923-930.

Chessick, C. A., Perlick, D. A., Miklowitz, D. J., Kaczynski, R., Allen, M. H., Morris, C. D.,...Group, S.-B. F. (2007). Current suicide ideation and prior suicide attempts of bipolar patients as influences on caregiver burden. Suicide and Life-Threatening Behaviour, 37(4), 482-491.

Christensen, L. B., Johnson, R. B., \& Turner, L. A. (2010). Research methods, design and analysis (Eleventh ed.). Boston: Allyn \& Bacon.

Colom, F., \& Berk, L. (2010). Psycho-education as a core element of psychological approaches for bipolar disorders. In L. N. Yantam \& M. Maj (Eds.), Bipolar disorder: clinical and neurobiological foundations. West Sussex: Wiley-Blackwell.

Corrigal, J., Ward, C., Stinson, K., Struthers, P., Frantz, J., Lund, C., Flisher, A.J., \& Joska, J. (2007). Final report: decreasing the burden of mental illness. Western Cape Burden of Disease Reduction Project. http://hdl.handle.net/20.500.11910/6073. Accessed 5 March 2016

Creswell, J. W. (2013). Qualitative inquiry and research design: choosing among five approaches. Thousand Oaks: Sage Publications.

Dalton, E. J., Cate-Carter, T. D., Mundo, D., Parikh, S. V., \& Kennedy, J. L. (2003). Suicide risk in bipolar patients: the role of co-morbid substance use disorder. Bipolar Disorder, 5, 58-61.

De Vos, A. S., Strydom, H., Fouché, C. B., \& Delport, C. (2011). Research at grass roots (Fourth ed.). Pretoria: Van Schaik.

Donalek, J. G., \& Soldwisch, S. (2004). Demystifying nursing research: an introduction to qualitative research methods. Urologic Nursing, 24(4), 354-356.

Fast, J. A., \& Preston, J. (2004). Loving someone with bipolar disorder: understanding and helping your partner. Oakland: New Harbinger Publications.

Fast, J. A., \& Preston, J. (2006). Take charge of bipolar disorder: a 4-step plan for you and your loved ones to manage the illness and create lasting stability. New York: Warner Wellness.

Ferrari, A. J., Stockings, E., Khoo, J., Erskine, H. E., Degenhardt, L., Vos, T., \& Whiteford, H. A. (2016). The prevalence and burden of bipolar disorder: findings from the Global Burden of Disease Study 2013. Bipolar Disorders, 18, 440-450.

Flisher, A. J., Corrigall, J., Bradshaw, D., Schneider, M., Lund, D. C., \& Stein, D. J. (2008). Mental health is integral to public health: a call to scale up evidence-based services and develop mental health research. South African Medical Journal, 98(6), 444-446.

Fujino, N., \& Okamura, H. (2009). Factors affecting the sense of burden felt by family members caring for patients with mental illness. Archives of Psychiatric Nursing, 23(2), 128-137.

Gonzalez, J. M., Perlick, D. A., Miklowitz, D. J., Kaczynski, R., Hernandez,M., Rosenheck, R. A., Culver, J. L., Ostacher, M. J., \& Bowden, C. L. (2007). Factors associated with stigma among caregivers of patients with bipolar disorder in the STEP_BD Study. Psychiatric Services, 58(1), 41-48.

Green, R. J., \& Thorogood, N. (2009). Qualitative methods for health research (Second ed.). London: Sage.

Halliwell, E. D., Main, L., \& Richardson, C. (2007). The fundamental facts: the latest facts and figures on mental health. Mental Health Foundation, 7, 1-84.

Haycock, D. A. (2010). The everything health guide to adult bipolar disorder (Second ed.). Massachusetts: 
Adams Media.

Herua, A.M., \& Ryan, C. E. (2004). Burden, reward and family functioning of caregivers for relatives with mood disorders: 1-year follow-up. Journal of Affective Disorders, 83, 221-225.

Last, C. G. (2009). When someone you love is bipolar: help and support for you and your partner. New York: The Guilford Press.

Lundt, C., Kleintjies, S., Kukuma, R., Flisher, A., \& MHaPP Research Programme Consortium. (2010). Public sector mental health systems in South Africa: inter-provincial comparisons and policy implementations. Social Psychiatry and Psychiatric Epidemiology, 45, 393-404.

Maji, K. R., Sood, M., Sagar, R., \& Khandelwal, S. K. (2012). A follow-up study of family burden in patients with bipolar affective disorder. International Journal of Social Psychiatry, 58(2), 2017-2223.

Meltzer, H., Singleton, N., Lee, A., Bebbington, P., Brugha, T., \& Jenkins, R. (2002). The social and economic circumstances of adults with mental disorders. London: Her Majesty's Stationary Office.

Miklowitz, D. J. (2010). Bipolar disorder: a family-focused treatment approach. New York: Guilford Press.

Miklowitz, D. J. (2011). The bipolar survival guide: what you and your family need to know (Second ed.). New York: Guilford Press.

Mondimore, F. M. (2006). Bipolar: a guide for patients and families. Maryland: The Johns Homkins University Press.

Nora, D., \& Volkow, M. D. (2010). National Institute on Drug Abuse: Co-morbidity, addiction and other mental illnesses. United State Department of Health and Human Service: National Institutes of Health. https://www.drugabuse.gov/publications/finder/t/162/research-reports. Accessed 13 March 2016

Perlick, D.A., Rosenheck, R.A., Clarkin, J.F., Maciejewski, P.K., Sirey, J., Struening, E. \& Link, B.G. (2004). Impact of family burden and affective response on clinical outcome among patients with bipolar disorder. Psychiatric Services, 55(9):1029-1035.

Perlick, D. A., Rosenheck, R. A., Miklowitz, D. J., Kaczynski, R., Link, B., Ketter, T.,Wisniewski, S.,Woff, N., \& Sachs, G. (2008). Caregiver burden and health in bipolar disorder: A cluster analytic approach. The Journal of Nervous and Mental Disease, 196(6), 484-491.

Reinares, M., Vieta, E., Colom, F., Martinez-Aran, A., Tottent, C., Comes, M., Goikolea, J. M., Benabarre, A., Daban, A., \& Sanchez-Moreno, J. (2006). What really matter to bipolar patients' caregivers: sources of family burden. Journal of Affective Disorders, 94, 157-163.

Republic of South Africa. (2002). Mental health care act. Pretoria: Government Printers. http://www.justice.gov.za/legislation/acts/2002-017mentalhealthcare.pdf. Accessed 11 October 2015

Sadock, B. J., \& Sadock, V. A. (2003). Mood disorders.. In Kaplan and Sadock's synopsis of psychiatry: behavioral sciences/clinical psychiatry (9th ed.). New York: Lippencott Williams and Wilkens.

Saegert, S., \& Evans, G. W. (2003). Poverty, housing niches and health in the United States. Journal of Social Issues, 59(3), 569-589.

Steel, Z., Marnane, C., Iranpour, C., Chey, T., Jackson, J. W., Patel, V., \& Silove, D. (2014). The global prevalence of common mental disorders: a systematic review and meta-analysis 1980-2013. International Journal of Epidemiology, 43(2), 476-493 Retrieved April 14 April, 2014, from htpps://doi.org/10.1093/ije/dyuo38.

Swartz, L., Breen, A., \& Flisher, A. (2005). How depressing: poverty, mental health and municipal services in South Africa. City of Cape Town: Cape Town. http://www.municipalservicesproject.org/msgpublications/occasional\%2opaper. Accessed 9 March 2016

Taylor, E. H. (2006). Atlas of bipolar disorders. London: Thompson Publishing Services.

Thompson, H., Petticrew, M., \& Douglas, M. (2003). Health impact assessment of housing improvements: incorporating research evidence. Journal of Epidemiology and Community Health, 57, 11-16.

Tranvag, O., \& Kristoffersen, K. (2008). Experience of being the spouse/cohabitant of a person with bipolar affective disorder: a cumulative process over time. Nordic College of Caring Science, 22(1):5-18.

Uys, L., \& Middleton, K. (2014). Mental health nursing: a South African perspective (Six ed.). Cape Town: Juta.

Vieta, E. (2009). Managing bipolar disorder in clinical practice (Second ed.). London: Current Medicine Group Ltd..

Vornic, E. S., \& Brown, L. A. (2006). Management of co-morbid bipolar and substance abuse. Journal of Clinical Psychiatry, 12, 2013-2017. 
Weich, L., \& Pienaar, W. (2009). Occurrence of co-morbid substance use disorder among acute psychiatric inpatients at Stikland Hospital in the Western Cape, South Africa. African Journal of Psychiatry, 12, $213-217$.

Whiteford, H. A., Degenhardt, L., Rehm, J., Baxter, A. J., Ferrari, J. A., Erskine, E. H., Charlson, F. J., Norman, R. E., Flaxman, A. D., Johns, N., Burstein, R., Murray, C. J., \& Vos, T. (2013). Global burden of disease attributable to mental and substance user disorders: findings from the Global Burden of Disease Study 2010. The Lancet, 382(9904), 75-1586. 